\title{
Latent Variables Definition for a New Mobility Model in Barcelona
}

\author{
Sara Ahetze Puignau \\ Centre for Innovation in Transport (CENIT) \\ Floridea Di Ciommo \\ Centre for Innovation in Transport (CENIT) \\ Sergi Saurí \\ Centre for Innovation in Transport (CENIT)
}

\begin{abstract}
In many European cities, mobility patterns are changing mainly due to advances in information and communications technology. Besides from this, people living in urban areas have now more transport mode alternatives to travel and the ownership of a vehicle is losing relevance to the modern world. In addition, the new generations value the time spent in the trip in a different way and they take advantage of travel time by means of connectivity (i.e. multitasking).
\end{abstract}

As a result of the complexity of transport supply and transport demand preferences, the choice of transport alternative does not currently depend only on traditional cost, time and socioeconomic aspects. Therefore, we have focused the investigation on attitudes, habits and perceptions, to incorporate latent variables in the individual utility function.

For this purpose, we have designed a web-based survey, based on qualitative in-depth interviews that revealed indicators of the travellers of Barcelona. The first section includes individual questions about a recent trip experience and the second part tests attitudinal aspects. A principal component analysis of the items asked in the attitudinal section has been carried out, obtaining 11 relevant factors that allocate respondents to different groups of users according to their attitudes and perceptions.

The results show that in Barcelona, users, especially millennials, take advantage of new technologies in their journeys, their time perception changes if they do activities during the trip and they perceive car and bike sharing as a good mobility solution instead of the ownership and use of a private car.

\section{INTRODUCTION \& BACKGROUND}

Mobility patterns in large European cities are becoming increasingly complex. This complexity concerns daily transport mode and route choices, and is growing due to information technology, the growing array of travel alternatives and the way in which new 
generations perceive and make use of time spent travelling.

Research on travel behaviour attempts to capture this inherent complexity in the choice of transportation and its determinants, with the aim of obtaining an effective tool that provides fundament to the choice, because understanding the modal choice is a key element in the ability to model and predict demand.

For years, socioeconomic factors and attributes of transportation alternatives (instrumental variables) were considered key elements of many models that served as support to stakeholders in decision-making (Shiftan et al., 2008). The socioeconomic and demographic variables and the traditional attributes of time and travel costs have been very relevant to these models to explain mobility. However, there is growing recognition that when an individual makes a decision in our society, the interplay between different factors is becoming increasingly complex. Several authors have shown that attitudes and perceptions influence the user's election process regarding transportation modes (Ashok et al., 2002; Ben-Akiva et al., 2002).

After all, there are different travel patterns in homogeneous socioeconomic groups (van Wee, 2002). This indicates that the modelling of travellers' behaviour should not only focus on objective measures and structural variables, but also in variables addressing attitudes, personal attributes or even lifestyles (van Acker et al., 2011). Segmentation approaches have been a subject of interest in regard to segmentation based on attitudes (Shiftan et al., 2008; Marco and Mokhtarian, 2009), showing that these market segmentations are very useful for identifying potential modal shift users.

The literature has provided different ways to take into account, along with the effect of traditional variables, these psychometric or unmeasurable variables in the choice model (Greene, 1984; Bollen, 1989; Keane, 1997). However, in recent years the use of hybrid models that integrate discrete choice models with latent variable models has gained popularity, aiming to turn abstract attributes into measurable variables so that they can be included as part of the utility. Thus, both known and latent variables are included in the modelling. Ben-Akiva et al. (2012), Bahamonde-Birke and Ortúzar (2012), Daziano and Bolduc (2013), Di Ciommo et al. (2013), Glerum et al. (2014), Hess and Stathopoulos (2013), Kamargianni and Polydoropoulou (2014), Paulssen et al. (2014), Raveau et al. (2010), Vredin-Johansson et al. (2006) and Tam et al. (2010), among others, have theoretically and empirically proven the advantages of these types of models.

The aim of our research was to design a survey targeted at a future hybrid model for Barcelona and identify, within a part of the data set provided by the survey, the subjective indicators of travel attributes, some of which are identified as latent attributes.

The paper is divided into five sections. The second section, after the introduction, discusses 
attitudinal and behavioural indicator variables. The third section describes the research methodology used for the survey. Section 4 investigates the determinants of users' behaviour, and shows how the perceptions and attitudes identified using the principal components helps to find the relevant factors of users. Section 5 draws conclusions, finalizing with some future lines of research.

\section{RESEARCH METHODOLOGY AND SURVEY DEVELOPMENT}

After identifying, thanks to qualitative surveys, the Key Performance Indicators (KPIs) that are representative in the current modal choice (Creafutur, 2015), we were then able to define a quantitative survey. The analysis of the attitudinal part of the survey suggests a set of latent variables for modelling the mobility in Barcelona.

\subsection{Analysis of the qualitative interviews and KPIs}

The main objective was to understand and define the variables that affected the modal choice of Barcelona's travellers and should be included into the online survey. To define the KPIs, 14 individual qualitative interviews were conducted with daily users of public and private transport in Barcelona and 4 interviews with commuters with origins or destinations outside of Barcelona (Creafutur, 2015).

Different types of patterns have been identified based on the frequency of travel (routine or occasional trips) and the trip reason. Thus, three types of variables were identified: variables based on rational thought; those that were emotional, related to environment factors; and variables that were emotional from a perspective of feelings (stress, relaxation, etc.).

Conducting the interviews has proven interesting in avoiding, to the greatest extent possible, the questionnaire being influenced by the interviewer's point of view. Thus, thanks to the in situ interviews and an examination of existing literature, both essential, we had been able to define the travel experience we intend to portray. Therefore, these observations were important to increasing the probability of creating valid measures for the city, exploring a long list of potential variables that were then used to define the questionnaire.

\subsection{Online survey}

We had designed an online survey, based on the qualitative interviews using the emerging variables (e.g. knowledge and familiarity with the route or line to get to destination, privacy and control of the own space, weather conditions or need for an open space sensation). First, we defined the way in which the survey had to approach the experience of travel. Then we designed a questionnaire reflecting all the key points and factors that we extracted. 


\subsubsection{Study of travel experience}

As recently do some other authors like Bahamonde-Birke et al. (2015), we wanted to emphasize the difference between attitudes and perceptions. Users often have a predisposition or tendency to act in a certain way, depending on their individual experiences and personality (Pickens, 2005). In this case, the approach depends only on the individual, and attitudinal indicators are considered constant in each user for all alternatives.

But perceptions (although they are very close to attitudes) should be interpreted as the process through which each individual experiences their environment. It depends on both the individual and the stimuli around them (Bahamonde-Birke et al., 2015). To work with perceptions and perceptual indicators, it is necessary to propose a new set of indicators for each transport mode alternative that users face. On occasion their choices are not strictly governed by the expected reaction given their attitude.

Some latent variables refer to the attitude of the users with respect to the trip and others deal with their perceptions of each mode of transport. Thus, in the online survey we had questions of revealed preferences (preferences that are revealed by traveller habits) complemented with questions about the perceptions and attitudes toward their choices.

Once we were able to obtain the revealed preferences of the users, we asked about their stated preferences (choice preferences of users towards alternatives that the user has not experienced). With a Stated Choice (SC) experiment, the study can gather information about the preferences of individuals, based on a series of games, where individuals are forced to choose what they would do, facing a trade-off between different attributes and thus declaring their preferences regarding them.

It is necessary to be cautious with these types of questions, as they are linked to the image that individuals have of themselves about risk, moral satisfaction and the provision of public resources, all related to a possible enhancement of self-image. With this in mind, the hypothetical scenario can offer the respondents an opportunity to alter their image (Carlsson et al., 2010).

According to Carlsson et al. (2010), in the hypothetical case in which the election doesn't have any real cost, users often tend to focus on the benefits, without really being aware of the costs involved. In this way the survey would reveal more about the respondents' attitudes rather than their real preferences (Kahneman and Sugden, 2005). This is why, in order to measure the attribute of interest, the different alternatives have been shown together with the actual costs it would entail.

\subsubsection{Final design of the survey}

Having defined the scope of the survey, the questionnaire included three main sections: (i) 
questions on the users' profile and their experience of specific trips, (ii) attitudinal questions about their travels and their choice of mode, and (iii) experiment of choices made only to car users.

\section{$1^{\text {st }}$ part: User profiles and their revealed experience}

In the first part of the survey, we asked users about their personal characteristics, such as age, gender, educational level, employment status and access to different vehicles and services. Thus, the entire questionnaire was addressed to the individual. For example, owning a vehicle is not the same as having access to a vehicle.

The respondents have been asked about their most recent workday or weekend. It is important to note that information on travel must not be asked in general (i.e., in terms of average values), but must refer to a specific time milestone or a recent reference to avoid bias in the data (Ortúzar and Willumsen, 2011).

In this section we asked about each stage of the trips on that day, to then be able to map out a pattern for the trips and their motives and choices in each context. Thus, all available modes of transport and reasons for travel have been dealt with separately.

The information about time has also been questioned in a customized way for each mode of transport marked by the respondent; for example, in the case of cars, time spent parking and time spent in traffic jams, among others, and in the case of public transport, time required to access transportation or time spent in transfers. We have aimed to have a complete view of segregated journey times for each mode. How travel time is used in each mode or how certain stages of the journeys are perceived is changing a lot in the city with the use of new technologies, most especially among the Millennials (Mans et al., 2012).

\section{$2^{\text {nd }}$ part: Attitudinal and perception questions}

With regard to the attitudinal part, respondents had rated all the important variables chosen on a 5-point scale (from "strongly disagree" to "strongly agree"). 56 items had been raised, formulated in such a way that they would measure their attitude towards an individual factor or their perception of a service. They were originally grouped into 8 groups of variables based on the qualitative interviews (Table 1).

\begin{tabular}{|l|c|}
\hline Factor & $\mathbf{N}^{\mathbf{o}}$ of items \\
\hline Sensitivity to cost and time variables & 8 \\
\hline Comfort and convenience & 9 \\
\hline Information of travel modes and routes & 5 \\
\hline Image and attractiveness of transport modes & 2 \\
\hline Attitudes regarding the alternative choice & 15 \\
\hline Security during the trip & 5 \\
\hline
\end{tabular}




\begin{tabular}{|l|l|}
\hline Environment of the travel mode & 5 \\
\hline Feelings during the trip & 7 \\
\hline
\end{tabular}

\section{Table 1 - Travel components considered in the attitudinal questions}

In the case of any available information to carry out their trips, we measured user perception of these services and how technology affects these perceptions. In the case of comfort and convenience, certain items had been asked from an attitudinal point of view, such as the need for a neat appearance, and others from a perceptional standpoint, such as cleanliness or the feeling of open space.

The same occurs with the environment of transport mode, the image or appeal of the transport, security, the users' mood during the trips and attitudes when choosing a mode of transport, where some items measured the users' direct attitude and others their perception. Thanks to this combination of ways of asking about the items, we are able to not only measure the attitude of users regarding the decision variables, but also a set of feelings that the chosen transport provide them with.

\section{$3^{\text {rd }}$ part: Stated Choice Experiment}

Finally, a Stated Choice (SC) experiment was carried out on users who reported having used the car for any of their day trips. We proposed the SC just to car users with the aim of analysing the importance of car ownership and the fidelity to the car, to obtain the real potential users of sharing services. In the case in which the respondent, according to the attitudinal questions, would not give up on having own vehicle, the game was between the current situation and carpooling services. However, if the ownership of the car was not important for the respondent, the game was between the current situation and car sharing.

The question presented respondents with three scenarios, giving them a choice between their current situation (baseline) and two alternative services. The attributes associated with each option were the variable monthly cost of the use of the car, a fixed annual cost, and owning or not owning the car. These were identified in the literature as the factors that currently differentiate users from different car services (see for example Kim and Park, 2015). In the experiment, each of the three alternatives was described by a drawing and a description of the service in line with these attributes.

Attribute levels were linked to the current use of the car that respondents indicated. This means that although most of the SP experiments have levels set in advance for each sample of users, in our case the levels of attributes were not known in advance and were adapted to the respondent. Therefore, it was necessary to assume a priori levels to design the experiment. The defined costs were different depending on the hours travelled each month. It should be noted that all attribute levels were consistent with actual data on monthly hours and the cost of trips. Thus, for each choice, respondents were aware of the real tradeoff between costs and the ownership between services. 


\subsubsection{Survey implementation}

Respondents were chosen through the database panel of Netquest, an independent provider of online services for research and marketing in Spain, Portugal and Latin America. In Spain it has more than 150.000 panel members listed on the database. They have their own survey software (Survey Manager) and respondents are exclusively recruited by invitation (without voluntary registration), to ensure a proper representation of the sample and the reliability of the information.

In total 1022 users completed the survey, with an average duration of 25 minutes. From this sample, 222 users went on to complete the last task of the SC questionnaire, because they reported having used the car for any of their trips. Table 2 shows the distribution of the respondents' characteristics.

\begin{tabular}{|c|c|c|c|}
\hline \multicolumn{2}{|l|}{ Characteristics of the respondents } & \multirow{2}{*}{$\begin{array}{c}\mathbf{N} \\
529\end{array}$} & \multirow{2}{*}{$\begin{array}{c}\% \\
52 \% \\
\end{array}$} \\
\hline C & Male & & \\
\hline Gender & Female & 493 & $48 \%$ \\
\hline \multirow{5}{*}{ Age } & $14-17$ & 130 & $13 \%$ \\
\hline & $18-30$ & 268 & $26 \%$ \\
\hline & $31-45$ & 280 & $27 \%$ \\
\hline & $46-65$ & 228 & $22 \%$ \\
\hline & more than 66 & 116 & $11 \%$ \\
\hline \multirow{5}{*}{ Level of education } & Middle School & 115 & $11 \%$ \\
\hline & High School & 205 & $20 \%$ \\
\hline & University degree & 518 & $51 \%$ \\
\hline & Occupational training & 145 & $14 \%$ \\
\hline & Other & 39 & $4 \%$ \\
\hline \multirow{6}{*}{ Employment status } & Employed & 619 & $61 \%$ \\
\hline & Unemployed & 32 & $3 \%$ \\
\hline & Retired & 111 & $11 \%$ \\
\hline & Student & 206 & $20 \%$ \\
\hline & Housewife & 6 & $1 \%$ \\
\hline & Other & 33 & $3 \%$ \\
\hline \multirow{5}{*}{ Number of household members } & 1 & 86 & $8 \%$ \\
\hline & 2 & 315 & $31 \%$ \\
\hline & 3 & 291 & $28 \%$ \\
\hline & 4 & 266 & $26 \%$ \\
\hline & more than 4 & 64 & $6 \%$ \\
\hline \multirow{4}{*}{ Month income in household } & $1300 €$ or less & 152 & $15 \%$ \\
\hline & $1300-2500 €$ & 306 & $30 \%$ \\
\hline & $2500 €$ or more & 265 & $26 \%$ \\
\hline & No answer & 298 & $29 \%$ \\
\hline \multirow{2}{*}{ Accessibility } & Driving licence & 758 & $74 \%$ \\
\hline & Access to a usable car & 521 & $51 \%$ \\
\hline
\end{tabular}




\begin{tabular}{|l|c|c|} 
Access to a shared car & 157 & $15 \%$ \\
\hline $\begin{array}{l}\text { Access to a usable } \\
\text { motorcycle }\end{array}$ & 187 & $18 \%$ \\
\hline Access to a usable bicycle & 400 & $39 \%$ \\
\hline Private parking lot & 414 & $41 \%$ \\
\hline
\end{tabular}

\section{Table 2 - Summary of respondents characteristics}

Concerning the socio-economic characteristics, the rate of women and men is almost the same. The range of ages is similar; the majority of the respondents consist of people whose age is between 31 and 45 years old, but it is remarkable the high proportion of young people in the survey. It represents one of the first survey in Europe including people beyond 14 years old. Most of the respondents present an educational level higher that High School $(85 \%)$ and the majority of the respondents $(61 \%)$ are employed. The number of household members is high in contrast with the month income in household.

Finally, a high proportion of the respondents have a driving licence $(74 \%)$, a half of the respondents have access to a car for their displacements and a $41 \%$ of respondents have a private parking lot. It means that there is a high percentage of respondents who are oriented to the car. It is also high the proportion of respondents with access to a bicycle (39\%).

\section{ANALYSIS OF RESPONDENTS’ATTITUDES AND DISCUSSION}

The first main goal of our survey was to capture the users' views and preferences of different transport modes and to identify their attitudes and perceptions of some important factors that define the travel experience. Moreover, the survey aimed to verify these main factors or dimensions as the ones that explain the decision of each type of user.

Due to the number of variables and data we collected from the survey, it is important to analyse what elements have resulted in being relevant in the travel experience. In the exploratory data analysis, a Principal Component Analysis have been undertaken, where the dimensionality of the data set have been reduced. This technique is used to find the causes of variability in a data set, detecting structural relationship among the variables while retaining the explanatory power of data. This result is obtained by projecting the data, according to which they are best represented in terms of least square (Washington et al., 2011).

The 56 items of the second part of the survey were analysed using factor analysis to guarantee a correct specification of the latent variables. The principal component analysis was conducted to explore the interrelationships among these attitudes and to define new combined indicators. To enable easy interpretation, the factors were rotated using Varimax technique so that each variable loaded heavily onto a single factor. 
In this way, instead of the eight dimensions considered in the survey, it was possible to identify eleven components explaining the $53 \%$ of the variance of the perceptual indicators (Table 4) without correlation between them. Table 3 presents the factor loadings extracted from the rotated component matrix for both types of indicators.

\begin{tabular}{|c|c|c|}
\hline Components (attitudes) & Items & $\begin{array}{l}\text { Factor } \\
\text { loadings }\end{array}$ \\
\hline \multirow{9}{*}{$\begin{array}{l}\text { 1. Sensitivity to cost and } \\
\text { time }\end{array}$} & Monetary cost & 0,464 \\
\hline & Travel time & 0,583 \\
\hline & Punctuality & 0,687 \\
\hline & Number of transfers & 0,654 \\
\hline & Knowledge of routes & 0,581 \\
\hline & Frequency & 0,722 \\
\hline & Proximity of the stops & 0,708 \\
\hline & Real time information at stops & 0,467 \\
\hline & Accessibility & 0,329 \\
\hline \multirow{6}{*}{ 2. Loyalty to the car } & Parking as an incentive & 0,574 \\
\hline & Not being altruistic in the election & 0,678 \\
\hline & Shift depending on facilities to bike & 0,535 \\
\hline & Punctuality depending on schedule & 0,370 \\
\hline & Shift depending on parking & 0,497 \\
\hline & Own vehicle & 0,678 \\
\hline \multirow{4}{*}{$\begin{array}{l}\text { 3. Flexibility and tendency } \\
\text { to change the travel mode }\end{array}$} & Flexibility in return trip & 0,487 \\
\hline & Shift depending on congestion & 0,418 \\
\hline & Shift depending on weather & 0,728 \\
\hline & Shift depending on mental conditions & 0,726 \\
\hline \multirow{4}{*}{ 4. Time using } & To use travel time to work & 0,448 \\
\hline & New technologies travelling & 0,675 \\
\hline & Careless of driving & 0,485 \\
\hline & Allow distractions & 0,635 \\
\hline \multirow{4}{*}{$\begin{array}{l}\text { 5. Awareness of shared } \\
\text { economy }\end{array}$} & Awareness of pollution & 0,375 \\
\hline & Share vehicles to reduce cost & 0,693 \\
\hline & Shift depending on health & 0,396 \\
\hline & Parking facilities as incentive to share & 0,561 \\
\hline \multirow{3}{*}{$\begin{array}{l}\text { 6. Concerns about big city } \\
\text { problems }\end{array}$} & Less polluting vehicle preference & 0,458 \\
\hline & Road congestion & 0,525 \\
\hline & Parking as a problem & 0,658 \\
\hline \multirow{3}{*}{ 7. Technology friendly } & Online information of routes & 0,562 \\
\hline & App for the availability of vehicles/parking & 0,719 \\
\hline & App to pay parking & 0,697 \\
\hline
\end{tabular}




\begin{tabular}{|c|c|c|}
\hline \multirow{2}{*}{$\begin{array}{l}\text { 8. Need of freedom } \\
\text { sensation }\end{array}$} & Relaxing time & 0,643 \\
\hline & Independence & 0,470 \\
\hline Components (perceptions) & Items & $\begin{array}{c}\text { Factor } \\
\text { loadings }\end{array}$ \\
\hline \multirow{8}{*}{ 9. Each mode's environment } & Open space sensation & 0,439 \\
\hline & Pleasing surroundings & 0,673 \\
\hline & Design of vehicles & 0,645 \\
\hline & Security guard & 0,467 \\
\hline & Transport driver presence & 0,457 \\
\hline & Abruptness of drivers & 0,468 \\
\hline & Privacy traveling & 0,496 \\
\hline & Own space without stress & 0,619 \\
\hline \multirow{9}{*}{ 10. Comfort } & Cleanliness & 0,447 \\
\hline & Temperature & 0,444 \\
\hline & Ventilation & 0,436 \\
\hline & Noise & 0,645 \\
\hline & Neat appearance & 0,484 \\
\hline & Seat availability & 0,520 \\
\hline & Phone coverage & 0,600 \\
\hline & Free $\mathrm{WiFi}$ & 0,616 \\
\hline & Extend service hours & 0,362 \\
\hline \multirow{4}{*}{$\begin{array}{l}\text { 11. Service level of public } \\
\text { transport }\end{array}$} & Easiness to pay & 0,407 \\
\hline & Safety in stops & 0,765 \\
\hline & Safety at night & 0,746 \\
\hline & Interaction with others in public transport & 0,401 \\
\hline
\end{tabular}

Table 3 - List of items classified into eleven travel components, grouped into attitudes related components and perceptions related components

\begin{tabular}{|l|c|c|c|}
\hline Components & $\begin{array}{c}\text { Eigen } \\
\text { value }\end{array}$ & $\begin{array}{c}\text { Variance } \\
\text { explained } \\
(\boldsymbol{\%})\end{array}$ & $\begin{array}{c}\text { Cumulated } \\
\text { variance } \\
\text { explained } \\
\mathbf{( \% )}\end{array}$ \\
\hline 1. Sensitivity to cost and time & 12,007 & 21,441 & 21,441 \\
\hline 9. Each mode's environment & 3,798 & 6,783 & 28,224 \\
\hline 10. Comfort & 2,503 & 4,469 & 32,694 \\
\hline 6. Concerns about big city problems & 2,069 & 3,695 & 36,388 \\
\hline 2. Loyalty to the car & 1,619 & 2,892 & 39,280 \\
\hline 3. Flexibility and tendency to change the travel mode & 1,521 & 2,716 & 41,996 \\
\hline 4. Time using & 1,410 & 2,517 & 44,513 \\
\hline 7. Technology friendly & 1,331 & 2,377 & 46,890 \\
\hline 5. Awareness of shared economy & 1,207 & 2,156 & 49,046 \\
\hline
\end{tabular}




\begin{tabular}{|l|l|l|l|}
\hline 11. Service level of public transport & 1,151 & 2,056 & 51,102 \\
\hline 8. Need of freedom sensation & 1,024 & 1,829 & 52,931 \\
\hline
\end{tabular}

Table 4 - Explained variance of each component of the principal component analysis

Regarding the attitudinal indicators, the first factor is identified as the "sensitivity to cost and time", as it is related to the importance given to cost and time indicators during the trip. This component explains the $21 \%$ of the variance of the data. The second component is associated with the "loyalty to the car", including a positive predisposition toward automobiles, and the third component is related to individuals who have great "flexibility and tendency to change the travel mode". These results are interesting for our analysis as it was possible to identify a non-alternative and an alternative related attitude. The factor four is "time using" related, joining the use of the travel time to work or to the use of new technologies (i.e. multitasking), with careless of driving and also allowing distractions while travelling.

The factor five is related to the appreciation for the development of services that take into account the "awareness of shared economy". In the same line, the sixth factor shows "concerns about big city problems", such as pollution, congestion and parking problems. These two components are interesting to evaluate future strategies in the city. The eighth component comprises the "technology friendly" attitudes, and finally, the last component added the value of the "need for freedom sensation" during the trips.

According to the travel perceptions, the ninth component is called "each mode's environment", as it is associated with situations causing privacy, security, stress, open space sensation and attractiveness during the trip. The tenth factor comprises the "comfort" items, such as cleanliness, temperature, noise, seat availability etc. These two factors explain another $11 \%$ of the variance. Finally, the factor eleven refers to the "service level of public transport", as the easiness to pay or safety travelling.

The attitudinal factors uncovered as part of this study were compared to those reported by other similar studies. Sensitivity to travel time or to transportation cost are common factors that emerged from this research as well as from Lieberman et al. (2001) or Proussaloglou et al. (2001). The willingness to use a mode and the loyalty to the mode are important attitudinal constructs uncovered by the analysis presented in this research, a finding supported by Shiftan et al. (2008) and Shiftan et al. (2015). Lieberman et al. (2001) and Popuri et al. (2011) also found concern for the comfort and the perceived safety in the level of service of public transport.

However, there are some new factors reported by this research as the concerns about big city problems, the time using, the technology friendly attitude and the awareness of shared economy. These variables may be emerging from a new paradigm of mobility in big cities like Barcelona. This has been verified by analyzing the differences of these new factors 


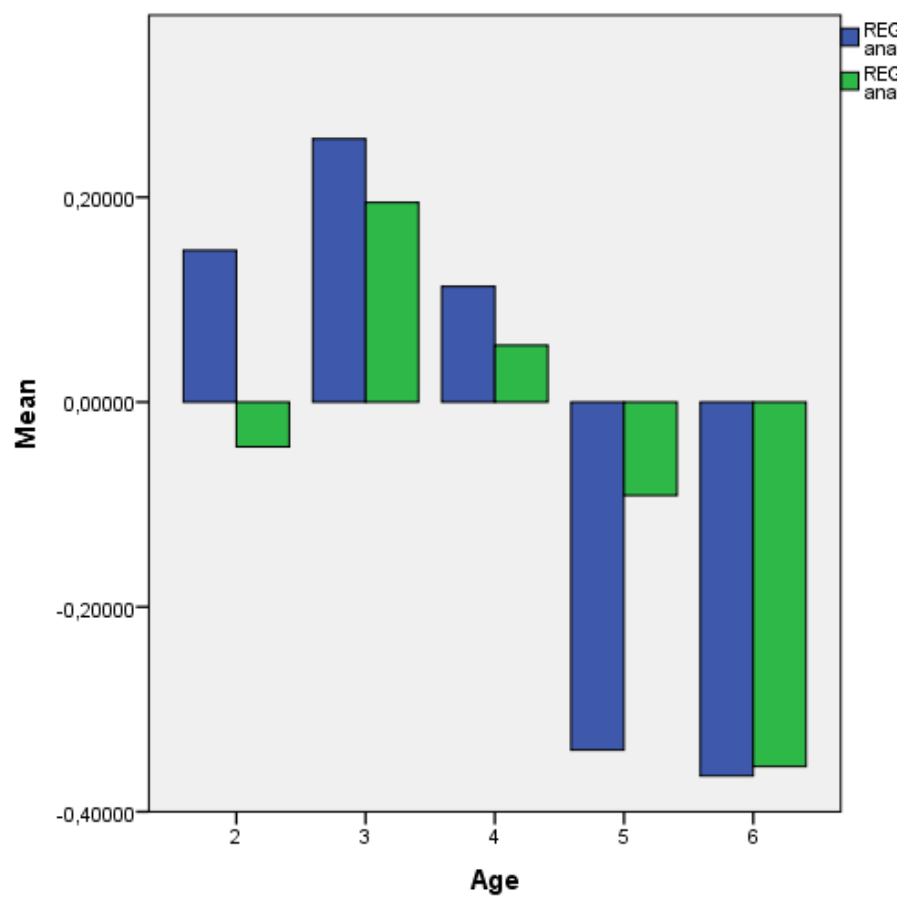

Age:

$2=14$ to 17

$3=18$ to 30

$4=31$ to 45

$5=46$ to 65

$6=66$ and beyond

Fig. 1 -Mean of "time using" (blue) factor and "technology friendly" (green) factor loadings according to the age.

We can see that the attitude about the use of travel time (blue in Figure 1) is different according to the age. Young people valuate positively to use the travel time to work or to enjoy new technologies and they like the modes that allow distractions and to be careless of driving. Moreover, regarding the technology friendly factor (green in Figure 1) they are in favour of having applications to search vehicles or to pay parking, as they also see useful the online information of transport routes. The exception would be the teenagers between 14 and 17 because they do not have the need to use such applications, even if they have a positive reaction to the use of technologies in travel time.

\section{CONCLUSIONS}

This article presents, firstly, a methodology for conducting surveys aimed at obtaining not only socioeconomic and objective variables concerning travelling, but also user attributes and perceptions when choosing their travel method. The respondents have been specifically asked about their travel patterns for daily journeys, including all travel modes and the reasons for travelling. Afterwards, ratings on the various attributes considered were obtained in order to extract subjective indicators for their choices.

Once the survey was completed, a factor analysis of the items asked in the attitudinal section has been carried out, obtaining 11 relevant factors that group the subjective 
indicators showing correlation. On the one hand, factors relating to user attitudes have included concerns about big city problems, loyalty to their cars, flexibility and a tendency to change travel modes, the use of time, being a lover of technology, an awareness of shared economy, and the feeling of freedom during the trip. On the other hand, the factors resulting from user perceptions of the alternatives have included factors related to costs and time, each mode's environment, the comfort and service level of public transport.

These factors have proven to be consistent with what has been read in literature; see Lieberman et al. (2001) and Shiftan et al. (2015), among others. Thus, we have obtained possible latent variables that could improve a discrete choice model for Barcelona.

Our empirical analysis shows evidence that supports the thesis that attitudes can affect the way in which different individuals attribute certain values to a given alternative. In the same vein, it is shown that perceptions could explain a significant portion of the variability that is normally seen for the alternative concrete variables. Therefore, besides presenting a methodology for obtaining latent variables, this article provides an initial insight into how attitudes and perceptions can explain the selection process for the travel mode, serving as a first step towards a hybrid model to explain the travel behaviour of the users in the city.

The results show that in Barcelona, users, especially millennium users, take advantage of new technologies in their journeys, their time perception changes if they do activities during the trip and they perceive car and bike sharing as a good mobility solution instead of the ownership and use of a private car.

\section{ACKNOLEDGEMENTS}

The authors acknowledge the financial and professional support provided by Volkswagen for the "New Paradigm for Urban Mobility in Barcelona-Limit of Modal Changes" project.

\section{REFERENCES}

ASHOK, K., DILLON, W.R. and YUAN, S. (2002). Extending Discrete Choice Models to Incorporate Attitudinal and Other Latent Variables. Journal of Marketing Research. Vol. XXXIX (February 2002), 31-46

BAHAMONDE-BIRKE, F. J. and ORTÚZAR, J.D. (2014). On the variability of hybrid choice models. Transportmetrica: Transport Science, Volume 10, Issue 1, 2014

BAHAMONDE-BIRKE, F.J., UWE, K., HEIKE, L. and ORTÚZAR, J.D. (2015) About attitudes and perceptions: Finding the proper way to consider latent variables in discrete choice models. Discussion Papers, Deutsches Institut für Wirtschaftsforschung, No. 1474

BEN-AKIVA, M.E., WALKER, J.L., BERNARDINO, A.T., GOPINATH, D.A., MORIKAWA, T. and POLYDOROPOULOU, A. (2002). Integration of choice and latent 
variable models. In H.S. Mahmassani (ed.), In Perpetual Motion: Travel Behaviour Research Opportunities and Challenges. Pergamon, Amsterdam.

BEN-AKIVA, M., DE PALMA, A., MCFADDEN, D., ABOU-ZEID, M., CHIAPPORI, P.A, DE LAPPARENT, M., DURLAUF, S.N., FOSGERAU, M., FUKUDA, D., HESS, S., MANSKI, C., PAKES, A., PICARD, N. and WALKER, J. (2012). Process and context in choice models. Marketing Letters Vol. 23, No. 2, Special Issue on the 8th Triennial Invitational Choice Symposium: Key Largo, 2010 (June 2012), pp. 439-456

BOLLEN, K.A. (1989). Structural Equations with Latent Variables. John Wiley and Sons, Chichester.

CARLSSON, F., DARUVALA, D. and JALDELL, H. (2010) Do you do what you say or do you do what you say others do? Journal of Choice Modelling, 3(2), pp 113-133.

CREAFUTUR (2015). KPI's for the new mobility paradigm. Qualitative results. Universitat Politècnica de Catalunya. July, 2015

DAZIANO, R.A. and BOLDUC, D. (2013). Incorporating pro-environmental preferences towards green automobile technologies through a Bayesian hybrid choice model. Transportmetrica: Transport Science, 9A, 74-106

DI CIOMMO, F., MONZON, A. and FERNANDEZ-HEREDIA, A. (2013). Improving the analysis of road pricing acceptability surveys by using hybrid models. Transportation Research: Part A: Policy Practice, 49, 302-316.

GLERUM, A., ATASOY, B. and BIERLAIRE, M. (2014). Using semi-open questions to integrate perceptions in choice models. J. Choice Modell, 10, 11-33.

GREEN, P. (1984). Hybrid models for conjoint analysis: an expository review. Journal of Marketing Research 21,155-169.

HESS, S. and STATHOPOULOS, A. (2013). A mixed random utility-random regret model linking the choice of decision rule to latent character traits. J. Choice Modell, 9, 27-38.

KAHNEMAN, D. and SUGDEN, R. (2005) Experienced utility as a standard of policy evaluation. Environmental and Resource Economics, 32(1), 161-181.

KAMARGIANNI, M. and POLYDOROPOULOU, A. (2014). Development of a hybrid choice model to investigate the effect of teenagers' attitudes towards walking and cycling on mode choice behavior. Transportation Research Record: Journal of the Transportation Research Board, 2382, 151-161 
KEANE, M.P. (1997). Modelling heterogeneity and state dependence in consumer choice behaviour. Journal of Business and Economic Statistics 153, 310-327.

KIM, D., KO, J. and PARK, Y. (2015). Factors affecting electric vehicle sharing program participants' attitudes about car ownership and program participation. Transportation Research Part D 36, 96-106

LIEBERMAN, W., SCHUMACHER, D., HOFFMAN, A. and WORNUM, C. (2001). Creating a new century of transit opportunity: strategic planning for transit. Transportation Research Record: Journal of the Transportation Research Board, 1747, 60-67

MANS, J., INTERRANTE, E., LERN, L., MUELLER, J. and LAWRENCE, M. (2012). Next Generation of Travel Behavior - Potential Impacts Related to Household Use of Information and Communication Technology. Transportation Research Record: Journal of the Transportation Research Board, No. 2323, pp. 90-98

MARCO, D. and MOKHTARIAN, P.L. (2009) Grouping Travelers on the Basis of their Different Car and Transit Levels of Use. Transportation 36, 455 - 467

ORTÚZAR, J. de D. and WILLUMSEN, L.G (2011). Modelling Transport. Fourth Edition, John Wiley and Sons, Chichester.

PAULSSEN, M., TEMME, D., VIJ, A. and WALKER, J. (2014). Values, Attitudes and Travel Behavior: A Hierarchical Latent Variable Mixed Logit Model of Travel Mode Choice. Transportation, 41, 873-888.

PICKENS, J. (2005). Organizational Behavior in Health Care. Jones and Bartlett Publishers, Sudbury, MA, USA.

POPURI, Y., PROUSSALOGLOU, K., AYVALIK, F.K. and LEE, A. (2011). Importance of traveller attitudes in the choice of public transportation to work: findings from the Regional Transportation Authority Attitudinal Survey. Transportation (2011), 38, 643-661

PROUSSALOGLOU, K.E., VAIDYA, R., HASKELL, K. and BEN-AKIVA, M. (2001). An attitudinal market segmentation approach to commuter mode choice and transit service design. Proceedings of the 2001 Annual Transportation Research Board Meeting, Washington, DC (2001)

RAVEAU, S., ALVAREZ-DAZIANO, R., YÁÑEZ, M.F., BOLDUC, D. and ORTÚZAR, J. de D. (2010). Sequential and simultaneous estimation of hybrid discrete choice models: some new findings. Transportation Research Record 2156, 131-139. 
SHIFTAN, Y., OUTWATER, M.L. and ZHOU, Y. (2008). Transit Market Research Using Structural Equation Modelling and Attitudinal Market Segmentation. Transport Policy, Vol. 15, No. 3, pp. 186-195

SHIFTAN, Y., BARLACH, Y. and SHEFER, D. (2015). Measuring Passenger Loyalty to Public Transport Modes. Journal of Public Transportation, Vol. 18, No. 1

TAM, M.L., LAM, W.H.K. and LO, H.P. (2010). Incorporating passenger perceived utility service quality in airport ground access mode choice model. Transportmetrica: Transport Science, 6, 3-17.

VAN ACKER, V., MOKHTARIAN, P.L and WITLOX, F. (2011). Going soft: on how Subjective Variables Explain Modal Choices for Leisure Travel. EJTIR 11(2), April 2011, pp. $115-146$

VAN WEE, B. (2002). Land use and transport: Research and policy challenges. Journal of Transport Geography, vol. 10, pp 259-271

VREDIN-JOHANSSON, M., HELDT, T. and JOHANSSON, P. (2006). The effects of attitudes and personality traits on mode choice. Transportation Research, 40A, 507-525.

WASHINGTON, S.P., KARLAFTIS, M.G. and MANNERING, F.L. (2011). Statistical and econometric methods for transportation data analysis. Second Edition, Chapman \& Hall, Boca Raton. 